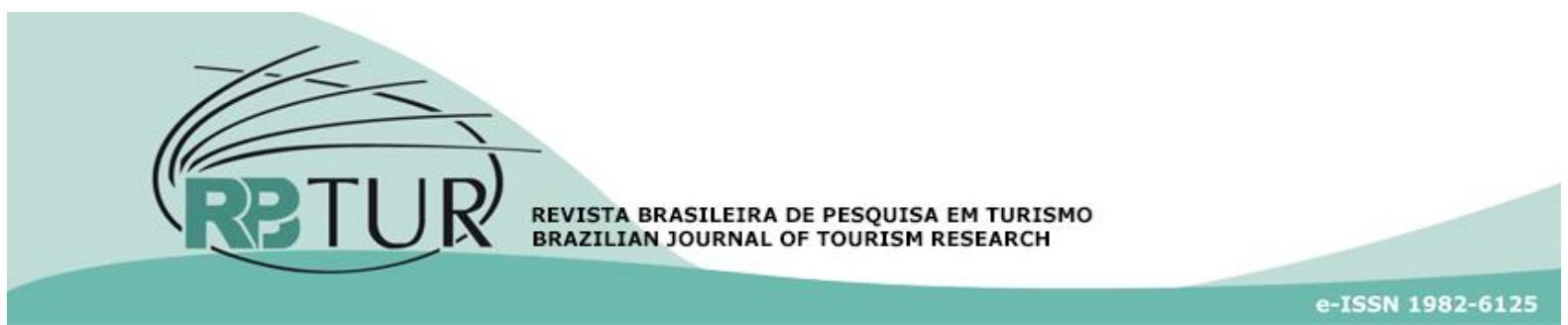

Artigo

DOI: http://dx.doi.org/10.7784/rbtur.v11i2.1309

\title{
Imagem e identidade turísticas relacionadas às práticas e bens culturais percebidas pelos residentes: perspectivas a partir da cidade de Blumenau, Santa Catarina, Brasil
}

\author{
Tourist image and identity related to practices of cultural objects \\ perceived by residents: perspectives from the city of Blumenau, \\ Santa Catarina, Brazil
}

\section{Imagen e identidad turísticas relacionadas a las prácticas y bienes culturales percibidos por los residentes: perspectivas a partir de la ciudad de Blumenau, Santa Catarina, Brasil}

\author{
Fabricia Durieux Zucco ${ }^{1}$ \\ Cynthia Morgana Boos de Quadros ${ }^{2}$ \\ Juliane Regina Schmitt ${ }^{3}$ \\ Thamires Foletto Fiuza ${ }^{4}$
}

Resumo: Propósito do tema: O crescimento do turismo proporcionou um grande aumento dos produtos turísticos que são ofertados no mercado. Antes de tomar a decisão, acerca de sua viagem e diante de tantas opções, o turista busca se informar sobre os mais variados destinos. A imagem de destino, criada por meio dessa busca, é um estímulo fundamental para o turista. Embora exista uma variedade de fatores que compõem uma imagem de determinado destino, são os seus elementos próprios que constituem a sua identidade cultural. Criar uma identidade de um lugar, envolve também a participação dos residentes do destino. Objetivo: Esse estudo busca analisar a cultura cervejeira, como uma possível identidade cultural de Blumenau e, para tanto, leva em conta as atitudes dos residentes. Metodologia e abordagem: A pesquisa é considerada exploratória e descritiva, com

1 Universidade do Vale do Itajaí (UNIVALI). Balneário Camboriú, SC, Brasil e Universidade Regional de Blumenau (FURB). Orientação na concepção e desenho do trabalho científico, tratamentos estatísticos, análise dos dados e validação das hipóteses.

2 Universidade Regional de Blumenau (FURB). Blumenau, SC, Brasil. Concepção da fundamentação teórica, elaboração da escala, coordenação de todas as atividades de campo/tabulação e revisão crítica do trabalho final.

3 Universidade Regional de Blumenau (FURB). Elaboração do referencial teórico, coleta dos dados, análise dos dados dos dados, redação do trabalho.

4 Universidade do Vale do Itajaí (UNIVALI). Elaboração da fundamentação teórica, revisão crítica do trabalho, redação do trabalho, preparação do artigo científico.

Artigo recebido em: 20/02/2017. Artigo aceito em:21/04/2017. 
método quantitativo. A partir da revisão da literatura sobre o assunto, doze hipóteses foram estabelecidas. Realizou-se a coleta e análise de dados que contou com os seguintes procedimentos estatísticos: Alfa de Cronbach, a Correlação de Spearman e o teste de hipóteses, por meio do programa SSPS. Resultados: Os resultados, obtidos na pesquisa, confirmaram sete, das doze hipóteses, o que indica a existência de relações positivas entre a influência dos hábitos dos residentes e as dimensões da identidade de Blumenau. Originalidade: Conclui-se que é possível a utilização da cultura cervejeira como uma identidade cultural da cidade, o que a torna adequada à sua promoção turística.

Palavras-chave: Identidade cultural. Cultura Cervejeira. Promoção turística.

Abstract: Proposal: The growth of tourism has led to a large increase of tourism products that are offered on the market. Before making the decision, about your trip and facing so many choices, the tourist seeks the information about the various destinations. The destination image created through this quest is an essential stimulus for the tourist. Although there is a variety of factors that make up a given destination image, it is its own elements that constitute its cultural identity. Create an identity of a place, it also involves the participation of the residents of the destination. Objective: This study seeks to analyze the brewing culture, as a possible cultural identity of the city of Blumenau and therefore takes into account the attitudes of the residents. Methodological Design: The research is considered exploratory and descriptive, with quantitative method. From the review of the literature on the subject, twelve hypotheses were established. The data collection and analysis were made using the following statistical procedures: Cronbach's Alpha, Spearman's correlation and the hypothesis test, using the SSPS program. Results: The results, obtained in the research, confirmed seven of the twelve hypotheses indicating the existence of positive relations between the influence of the habits of the residents and the dimensions of the identity of Blumenau. Originality: It is concluded that is possible to use the brewery culture as a cultural identity of the city, which makes it suitable for the tourist promotion.

Keywords: Cultural identity. Brewing culture. Tourism promotion.

Resumen: Propósito del tema: El crecimiento del turismo proporcionó un gran aumento de los productos turísticos que se ofrecen en el mercado. Antes de tomar la decisión, en relación a su viaje y frente a tantas opciones, el turista procura informarse sobre los lugares o destinos más variados. La imagen de destino, creada mediante esa búsqueda, es un estímulo fundamental para el turista. Aunque exista una diversidad de factores que componen la imagen de un determinado destino, van a ser sus propios elementos que constituyen su identidad cultural. Elaborar la identidad de un lugar, también abarca la participación de los habitantes del destino. Objetivo: Este estudio analiza la cultura cervecera, como una posible identidad cultural de Blumenau y, para llevar a cabo esto, toma en consideración cuáles son las actitudes de sus residentes. Metodología y abordaje: Esta investigación es del tipo exploratoria y descriptiva, con uso del método cuantitativo. A partir da revisión de la literatura sobre el tema, doce hipótesis se establecieron y posteriormente se realizó la recaudación de los datos así como el análisis de éstos. Los procedimientos estadísticos utilizados fueron: Alfa de Cronbach, la Correlación de Spearman y la prueba de hipótesis, por medio del programa SSPS. Resultados: Los resultados, obtenidos en la investigación, señalan que se confirmaron siete de las hipótesis establecidas lo que indica que existen relaciones positivas entre la influencia de los hábitos o costumbres de los habitantes y las dimensiones de identidad de la ciudad de Blumenau. Originalidad: Se concluye que es posible el uso de la cultura cervecera como una identidad cultural de dicha ciudad, lo que la deja adecuada a hacerle propaganda turística.

Palavras clave: Identidad cultural. Cultura Cervecera. Propaganda turística. 


\section{INTRODUÇÃO}

A evolução da atividade turística proporcionou um crescimento na diversidade de produtos turísticos (Pérez-Nebra \& Rosa, 2008). Atualmente, existem muitos motivos para se deslocar de um lugar ao outro e esse fato é gerador de grande crescimento no segmento. No contexto econômico, o turismo mundial movimentou, em 2014, mais de US\$ 1 trilhão e, no Brasil, o segmento representa $3,6 \%$ do PIB - Produto interno bruto (Neto, 2015). O Anuário Estatístico de Turismo de 2015 (Brasil, 2015) revelou que, mais de 6,4 milhões de turistas, passaram pelo Brasil no ano de 2014 e em Santa Catarina foram mais de 156 mil turistas.

A promoção turística, que utiliza ferramentas para articular a imagem do destino à sua identidade cultural, constitui-se em um papel decisivo no desempenho apresentado entre os destinos, com o destaque dos aspectos positivos e a promoção da localidade (Lavandoski, Tonini, \& Barretto, 2012). Essa necessidade é justificada e defendida em diversas pesquisas realizadas nos últimos anos, em que os pesquisadores examinaram a área do turismo e a imagem do destino, bem como a identidade cultural e a participação dos residentes.

As diferentes abordagens de estudos acadêmicos, relacionados à imagem e a identidade de um destino, são citadas por alguns autores como Azambuja e Mecca (2017), Azevedo, Paes e Andrade (2014), Banducci Junior e Barreto (2001), Dias e Cassar (2006), Echtner e Ritchie (1991), Gallarza, Saura e
García (2002), Pérez-Nebra (2005), Stets e Biga (2003) e Williams (1995).

No campo das percepções dos residentes, Besculides, Lee e Mccormick (2002) consideram que o turismo promove inúmeros benefícios culturais. Existem outros estudos que se destacam, como os desenvolvidos por Andereck, Valentine, Knopf e Vogt (2005) que utilizaram a teoria da troca social, bem como os de Carniello e Santaella (2012), Choo e Park (2011), Lavandoski, Tonini e Barretto (2012), Nunkoo e Gursoy (2012) que também utilizaram a teoria da troca social e a teoria da identidade em seus estudos. Outros estudos importantes, que abordam o residente, são os de Fernandes, Castillo e Gândara (2016), Plummer, Telfer, Hashimoto e Summers (2005), Wang e Chen (2015), Williams, McDonald, Riden e Uysal (1995) e Zhang, Ryan e Cave (2016).

Cientes de que a imagem e a identidade de um destino estão relacionadas às práticas e bens culturais que identificam seus residentes, de acordo com os autores (Azevedo et al., 2014. Andereck et al., 2005. Dias \& Cassar, 2006; Fernandes et al., 2016), pode-se supor que os residentes que desfrutam e conhecem o produto característico da cidade, percebem uma maior relação do produto característico com o destino.

Com base nas ideias expostas, é possível refletir o quanto a cultura cervejeira está relacionada com a cidade de Blumenau, Santa Catarina (Brasil) e seus residentes, a ponto de ser ideal para sua promoção turística e de ser considerada a Capital Nacional da Cerveja. 
No que se refere a imagem de Blumenau, é importante conhecer a realidade do ponto de vista dos residentes. Observar se os residentes identificam a cultura cervejeira como elemento de identidade da cidade. Esse estudo contribui para que os setores públicos e privados trabalharem no fomento da atividade turística, com a utilização de uma comunicação coerente com o destino.

O objetivo desse trabalho é analisar, a partir das atitudes dos residentes, a cultura cervejeira como identidade cultural de Blumenau capaz de promover, turisticamente, a cidade. Por meio de testes de hipóteses, desenvolvidos com base em várias literaturas, verificou-se como a identificação e hábitos dos residentes, com relação à cerveja e ao chope artesanal, influenciam na percepção sobre a imagem de Blumenau, na sua participação em eventos culturais e no conhecimento acerca dos produtos turísticos.

O município de Blumenau se encontra localizado na região do Vale do Itajaí, Santa Catarina, Brasil (Figura 1). A cidade, que possui cerca de 334.002 habitantes, passou a ser considerada o destino indutor da Região Turística do Vale Europeu (Prefeitura Municipal de Blumenau, 2015). De acordo com o Plano Municipal de Turismo de Blumenau (Prefeitura Municipal de Blumenau, 2015), o destino apresenta muitos traços da cultura germânica, visíveis em distintos pontos da cidade e possui arquitetura, predominantemente, Enxaimel, artesanato, gastronomia e diversas manifestações culturais que remetem à cultura alemã.

Figura 1 - Localização da cidade de Blumenau, Santa Catarina

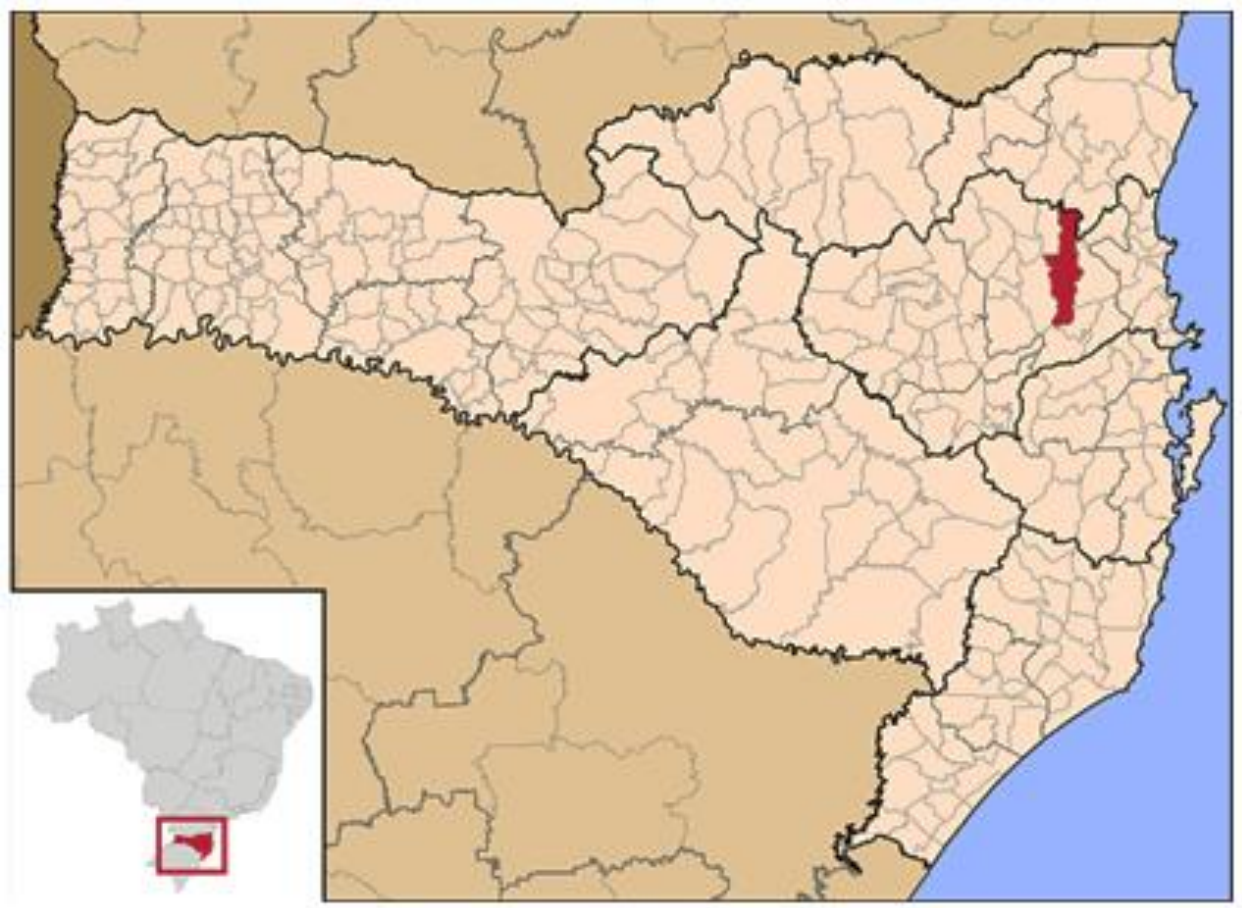

Fonte: Wikipédia (2017) 
A existência e consagração de tais traços germânicos no município e a sua estreita imagem de cidade nacional da cerveja, incentivaram, massivamente, o surgimento de atrativos, cervejarias artesanais e eventos com a temática germânica. Dentre tais atrativos, a Oktoberfest se destaca como o principal produto turístico do destino, é considerada, atualmente, o segundo maior festival típico alemão do mundo (Prefeitura Municipal de Blumenau, 2015) e atrai milhares de turistas para a cidade. Ademais, conta com uma instituição de ensino, especializada em cursos a respeito da produção da bebida, sedia, anualmente, o Festival Brasileiro da Cerveja, tem a primeira "micromalteria" do país e é sede de diversas "microcervejarias" artesanais, premiadas nacional e internacionalmente.

O presente estudo está estruturado em quatro seções: a primeira, é a apresentação dos objetivos gerais e específicos. A segunda, apresenta a revisão de literatura acerca da propaganda no turismo, formação da imagem e identidade do destino, participação dos residentes e eventos turísticos. A terceira, é uma exposição dos procedimentos metodológicos para a realização da pesquisa. A quarta, é a apresentação dos resultados descritivos da amostra, a Correlação de Spearman, o teste de hipóteses e a análise dos resultados. Os resultados apresentados, por meio deste estudo, constituem uma visão local atual, acerca da identidade cultural, e busca contribuir em pesquisas futuras sobre o assunto.

\section{O PRODUTO TURÍSTICO E A IDENTIDADE DO DESTINO}

O produto turístico difere dos demais produtos de consumo encontrados nas prateleiras. Não se trata de um produto que possa ser levado ao consumidor, ou seja, o cliente não pode comprar e consumir o produto turístico em qualquer lugar e nem mesmo experimentá-lo antes de decidir por sua compra. Devido a esse fato, Miranda e Miranda (1999: 122) confirmam que "qualquer atrativo turístico é um produto mais dependente de promoção do que os produtos de consumo comum", pois, diferentemente do produto turístico, aquele produto na prateleira nem sempre precisa de um material gráfico ou de um filme para estimular a sua compra.

Além de serem consideradas elementos que constituem o produto turístico, as atrações turísticas ainda possuem o potencial de refletir o carater intrínsico, distinto e único de uma comunidade, tanto no que se refere à parte cultural ou à ambiental. (Santos, Ferreira, \& Costa, 2014). Dentro desse contexto, um estudo realizado com turistas e residentes de Algarve - Portugal, para identificar quais eram os recursos nucleares do destino, constatou que os recursos identificados remetiam a elementos da paisagem cultural e natural. Como conclusão, verificou-se a existência de um conceito de paisagem cultural, no qual se deve basear o desenvolvimento de produtos turísticos inovadores. (Santos et al., 2014).

A culinária e a bebida local, de um determinado destino, são outros elementos 
que podem estar incorporados ao produto turístico, visto que os turistas procuram experiências autênticas e originais. $O$ consumo de alimentos e bebidas locais estabelece um vínculo do turista com a cultura do destino, como afirmam Plummer et al. (2005). A comercialização desses produtos também pode ajudar a promover e melhorar a identidade local. Afirmam, ainda, que os locais de fabricação dos produtos característicos de um destino podem ser vistos como atrativos turísticos do local. $\mathrm{O}$ indivíduo que o visita, cria a consciência da marca do destino e da imagem de qualidade que ele possui.

A cerveja, como produto característico de determinado destino, pode ser inserida em visitações às fábricas, na participação em festivais e shows de cerveja, nos quais é possível a degustação do produto da região que, muitas vezes, consiste no fator de motivação da visita de turistas ao destino. Plummer et al. (2005) investigaram os resultados do fluxo turístico nas cervejarias de Ontário, Canadá. Utilizaram-se de uma análise que buscou identificar o perfil dos visitantes de cervejarias da região e os meios pelos quais eles obtiveram informações sobre o destino. Avaliaram também, a importância dessas visitas no roteiro dos turistas não residentes. Tais informações contribuem para o reconhecimento do papel do turismo para as cervejarias.

A culinária e a bebida local são elementos incorporados ao produto turístico do destino, o que torna significante a identificação do residente com o produto característico do lugar e o seu conhecimento, uma vez que os turistas buscam consumir o que é próprio da cidade (Plummer et al., 2005). Para haver uma identificação do residente com o seu produto local, as características desses devem estar relacionadas com a imagem do destino que será promovida (Buosi, Lima, \& Silva, 2017; Pérez-Nebra, 2005). A partir das ideias expostas, estabeleceram-se as seguintes hipóteses:

H1 - Quanto maior a frequência do consumo de cerveja e de chope artesanal, tanto mais conhecidos, ficarão os produtos turísticos de Blumenau;

H2 - Quanto maior o número de marcas conhecidas de cerveja e de chope artesanal, tanto mais conhecidos, ficarão os produtos turísticos de Blumenau;

H3 - Quanto maior a expertise sobre cerveja e chope artesais, tanto mais conhecidos, ficarão os produtos turísticos de Blumenau;

H4 - Quanto maior a identificação com cerveja e chope artesais, tanto mais conhecidos, ficarão os produtos turísticos de Blumenau;

No que se refere ao uso de imagem do destino, pode-se afirmar, com base no estudo de Gallarza, Saura e García (2002) que existem três dimensões que relacionam as variáveis para a medição da imagem, são elas: a percepção do indivíduo, a dimensão em torno de objetos ou destinos e a relação de determinados atributos ou características. Os autores afirmam, ainda, que existe uma variedade de fatores que compõem a identi- 
dade de uma imagem de destino, o que se tornou uma área de substancial investigação.

A imagem de um destino tambem está vinculada às práticas e aos bens culturais que identificam seus residentes e que podem, eventualmente, atrair turistas. Azevedo, Paes e Andrade (2014) e, ainda, Buosi, Lima e Silva (2017) declaram que determinados elementos simbólicos de grupos sociais específicos passaram a identificar cidades e/ou países na promoção turística dos destinos. Pérez-Nebra (2005) argumenta que a imagem do destino é composta por vários elementos, tais como: os sentimentos, as emoções, as ideias, os prejulgamentos e os fatores psicológicos que exercem influência no desenvolvimento de uma campanha publicitária.

Os autores, Carniello e Santaella (2012), defendem a existência de três tipos de imagens turísticas, pautadas no estudo: a global, a tradicional e a atual. A imagem denominada global está relacionada à visão geral que o turista tem dos destinos que deseja conhecer; a tradicional é resultante das experiências vividas; e a imagem atual, como exposto anteriormente, representa o espaço criado pela mídia. Apesar da contribuição da propaganda para o turismo, os resultados do estudo de Carniello e Santaella (2012), realizados por intermédio de entrevistas com os turistas, demonstram que a imagem do destino turístico, percebida por eles, está mais associada às relações sociais e aos atributos físicos do que, propriamente, ao discurso da mídia.

O modelo conceitual dos fatores determinantes da imagem de um destino turís- tico, proposto por Mazzon e Vera (2008), evidenciou o aspecto "satisfação" como antecedente ao aspecto "lealdade" e "comprometimento". Estabelece que a imagem pode ser considerada um mediador entre a qualidade, a satisfação e a lealdade, pois representa as expectativas pós-consumo. De outro ponto de vista, Neiman, Geerdink e Pereira (2011) realizaram um estudo que revela o quanto a fotografia, como imagem do destino, é determinante no processo de motivação da atividade turística, em comparação à descrição do mesmo local. Os resultados apontam que as expectativas, as percepções e as motivações estão inseridas em um conjunto de sensações e experiências internalizadas. Os significados, atribuídos a esse conjunto, podem ser de natureza positiva, negativa ou neutra.

Echtner e Ritchie (1991) determinam que a imagem do destino, de fato, influencia o comportamento turístico e que os destinos com imagens positivas tendem a ser mais considerados e escolhidos pelos turistas, nesse processo de decisão. É válido destacar que a satisfação do turista depende da comparação entre as imagens formadas, com base nas expectativas e a imagem da realidade encontrada. Outro aspecto, para a questão da imagem do destino percebida pelo turista, é o relacionamento do indivíduo com seu espaço. A partir da decisão de viajar, o turista desenvolve necessidades de base e de prestígio que, combinadas com as características do local, criarão uma percepção sobre o destino, o que definará, ou não, a sua visita ao local (Neiman, Geerdink, \& Pereira, 2011).

Stets e Biga (2003), em seus estudos 
sobre a teoria da identidade, estabelecem 3 impressões: a primeira é o padrão, um conjunto de significados ligados à identidade do destino. A segunda é a avaliação, refletida diante do feedback de outros indivíduos. A terceira é a situação resultante da comparação entre a percepção e o padrão, em que se registra, o grau de discrepância entre os dois. A discrepância é expressa em forma de emoções, ou seja, quanto maior for a discrepância, tanto mais negativa será a emoção. Finalmente, a emoção resulta da comparação da percepção de entrada e do padrão de identidade.

Um dos fatos indicados no estudo de Andereck (2005), é a perda da identidade e cultura locais. Explica que os destinos com alto fluxo de turistas, atraem novos moradores e, assim, o aumento da população. Esse aumento de moradores, aliado a um planejamento medíocre por parte dos gestores do destino, acarretam na perda da identidade e da cultura da região. Dessa maneira, concluise que os residentes, estabelecidos por mais tempo em um determinado ambiente, são os responsáveis pela conservação da identidade e da cultura locais. Todavia, deve-se levar em consideração o que evidenciam Dias e Cassar (2006) em seus estudos, ou seja, o fato do visitante reconhecer as características da localidade e associar os benefícios, é um passo para a sua fidelização. A criação da identidade de um destino depende de seus residentes que devem assumí-la para que esse destino se consolide na imagem do turista. (Dias \& Cassar, 2006; Fernandes et al., 2016). Sobre a influência da identificação dos residentes com o seu destino e a identidade regional, no que se refere ao desenvolvimento do turismo, Williams et al. (1995) confirmaram, em seus estudos, que o tempo de residência está, mais fortemente, correlacionado com o sentimento de comunidade do que com qualquer identidade comunitária ou regional. A pesquisa com os residentes de cidades próximas ao Mt. Rogers National Recreation Area (NRA), localizado na Virgínia, constatou que residentes, favoráveis ao turismo, podem expressar laços mais fortes com o caráter regional do destino do que com a comunidade. $O$ estudo encontrou uma correlação mais elevada entre o tempo de residência e o sentimento da comunidade e uma fraca correlação entre tempo de residência e identidade regional.

$O$ residente também possui papel na identificação de elementos que tornam a região única. Santos et al. (2014), baseiam-se na premissa de que os recursos identificados pelos residentes e turistas são considerados recursos nucleares e podem servir de suporte no desenvolvimento de produtos turísticos inovadores. A autenticidade da imagem do destino depende muito da presença dos residentes nos locais, da sua relação e identificação com ele. Lavandoski, Tonini e Barretto (2012), identificaram o valor que o vinho tem para a região do Vale dos Vinhedos, como elemento de reforço à identidade local, pertencente aos descendentes de imigrantes italianos. Com o tempo, o vinho se transformou em um bem de valor e em um atrativo turístico da região.

Em outro estudo, também sobre o vi- 
nho como produto turístico, é possível reconhecer seu valor atrativo para a região da Colúmbia Britânica. A partir da perspectiva de desenvolvimento do turismo para a província, dados expostos por Williams e Kelly (2001) mostram o crescimento da indústria do vinho, tanto em quantidade, quanto em qualidade na sua produção e sugerem a existência de oportunidades consideráveis para capitalizar vinícolas, como forma de atrair visitantes para esses destinos rurais. Os autores afirmam que os moradores das regiões vinícolas têm a tendência a uma maior fidelidade com o produto do vinho e sua região.

Silva e Junior (2016) desenvolveram uma pesquisa com objetivo de analisar os fatores que influenciam o apoio dos residentes para o desenvolvimento do turismo religioso em Santa Cruz (RS), os resultados apontam que quanto mais os residentes perceberem os benefícios gerados pelo turismo, maior a propensão ao apoio comunitário para o desenvolvimento do turismo religioso.

Wang e Chen (2015) desenvolveram um estudo, referente ao turismo, que avalia se a identidade de um lugar pode afetar as atitudes dos residentes e evidencia a importância da atitude do residente para o desenvolvimento do turismo. As teorias utilizadas no estudo são a de lugar identidade e a da troca social, ambas se complementam na avaliação dessa atitude. Uma interação amigável entre os visitantes e residentes, por exemplo, cria um efeito significativo sobre a satisfação dos visitantes com o destino. Muitas vezes os interesses dos visitantes estão à frente das necessidades e preocupações dos residentes e podem provocar conflitos. Dessa maneira, é aconselhável e fundamental levar em consideração o ponto de vista dos residentes, para manter o seu apoio ao turismo.

Um estudo, desenvolvido por Nunkoo e Gursoy (2012) e aplicado na Ilha de Mauricio, constatou que a decisão dos residentes em apoiar o desenvolvimento se baseia nos benefícios esperados e que a influência da identidade de gênero, também incide sobre o apoio. Assim, percebe-se que a inclusão de fatores de identidade nos estudos pode meIhorar a previsão do comportamento de base, pois a teoria da identidade se constitui no pressuposto de que os indivíduos não se comportam de acordo com decisões discretas e pessoais. Eles são incorporados numa estrutura social que influencia o seu comportamento.

Com referência às estratégias de marca de um destino, Choo e Park (2011) apontam que a relação do residente com a marca do destino turístico, tem sido pouco explorada nas pesquisas em turismo. Em seus estudos, buscaram testar, empiricamente, o papel dos residentes na formação da marca do destino. Examinaram como a identificação dos moradores com o seu lugar, tem influência sobre os seus comportamentos. Os resultados da pesquisa indicam que, quanto mais o residente se identifica com a marca de destino, mais eles recomendam, positivamente, o local em que residem, agem gentilmente com os visitantes e desfrutam de mais atividades de turismo/lazer do seu lugar.

Compreende-se que a imagem e a identidade de um destino estão relacionadas às práticas e bens culturais que identificam seus residentes. De acordo com alguns auto- 
res (Andereck et al., 2005; Azevedo et al., 2014; Dias \& Cassar, 2006), pode-se supor que os residentes, que desfrutam e conhecem o produto característico da sua região, percebem uma maior relação do produto característico, com o destino. Assim, as seguintes hipóteses foram elaboradas:

H5 - Quanto maior a frequência de consumo de cerveja e de chope artesanais, tanto maior será a percepção da relação entre a cerveja artesanal e Blumenau;

H6 - Quanto maior o número de marcas conhecidas de cerveja e de chope artesanais, tanto maior será a percepção da relação entre a cerveja artesanal e Blumenau;

H7 - Quanto maior a expertise sobre cerveja e chope artesanais, tanto maior será a percepção da relação entre a cerveja artesanal e Blumenau;

H8 - Quanto maior a identificação com a cerveja e o chope artesanais, maior será a percepção da relação entre a cerveja artesanal e Blumenau.

Por outro lado, sabe-se que os festivais e eventos especiais exercem um importante papel na vida dos residentes. Além de proporcionarem atividades de lazer, movimentam a economia e melhoram a imagem do destino. Para os organizadores, os eventos e festivais são vistos como oportunidades de gerar receita para o destino. Para os residentes, eles representam opções de atividades de lazer e o compartilhamento de cultura. Nesse caso, existem duas visões diferentes sobre a finalidade de um evento ou festival: a dos organizadores e a dos residentes locais. Se o evento é organizado, unicamente, para gerar lucro, sua autenticidade é comprometida, além de ocorrer problemas como superlotação. No caso de ocorrer disparidade entre essas visões, os resultados do evento podem gerar insatisfação (Gursoy, Kim, \& Uysal, 2004).

O ponto de vista de Gursoy, Kim e Uysal (2004) sustenta que os eventos e festivais são vistos, pelos residentes, como oportunidades para a prática de atividades de lazer e compartilhamento da cultura. Os estudos de Zhang et al. (2016), também tratam da influência de um local sobre a vida dos residentes. Esse local pode ser considerado uma opção de lazer, uma diversão e um depósito cultural. A teoria de Choo e Park (2011) complementa e defende: quanto mais o residente se identifica com a marca do destino, tanto mais eles desfrutam das atividades de turismo/lazer do seu lugar.

Infere-se, a partir dessas concepções, que os residentes consideram festivais e eventos como atividades recreativas e desfrutá-las, pode favorecer o bem estar e a identificação dessas como um repositório cultural, em que a cultura tem a possibilidade de ser compartilhada. Os festivais e eventos movimentam a economia (Jackson, 2008) e, desse modo, praticam a comercialização de produtos turísticos. Com base nas ideias expostas, foram delineadas as seguintes hipóteses:

H9 - Quanto maior a frequência de consumo de cerveja e de chope artesanais, tanto maior será a presença emeventos turísticos de Blumenau; 
H10 - Quanto maior o número de marcas conhecidas de cerveja e de chope artesanais, tanto maior será a presença em eventos turísticos de Blumenau;

H11 - Quanto maior a expertise sobre a cerveja e sobre o chope artesanais, tanto maior será a presença em eventos turísticos de Blumenau;

H12 - Quanto maior a identificação com a cerveja e com o chope artesanais, tanto maior será a presença em eventos turísticos de Blumenau.

\section{PROCEDIMENTOS METODOLÓGICOS}

O presente estudo ocorreu basicamente em quatro etapas: revisão documental e bibliográfica, referente ao tema de pesquisa; seleção dos dados e variáveis, necessária para alcançar os objetivos propostos; análise dos dados coletados; e elaboração das considerações e referências.

A pesquisa bibliográfica e documental foi desenvolvida com a finalidade de analisar a importância da elaboração de estudos para a promoção turística, relacionados à cultura e à identidade de destinos. Outrossim, possibilitou, às pesquisadoras, a visualização de pesquisas emergentes referentes à temática e permitiu a elaboração das hipóteses testadas. Após essa primeira etapa, constatou-se que o levantamento de campo (survey), por meio da aplicação de questionário, seria o melhor instrumento, disponível, de coleta de dados para analisar a cultura cervejeira, como identidade cultural na cidade de Blumenau.
Sob a ótica metodológica, classificase, o presente estudo: como uma pesquisa básica descritiva, quando relacionado à natureza do estudo e como uma abordagem quantitativa, quando relacionado à abordagem do problema. Samara e Barros (2002) afirmam que esse método é realizado com o objetivo de responder à questão "Quanto?", para cada objetivo adotado. É realizado a partir da elaboração de uma amostra que represente a população. Na pesquisa quantitativa, os dados obtidos são resultantes de um grande número de respondentes.

$\mathrm{O}$ instrumento de coleta de dados da presente pesquisa foi elaborado com base nos seguintes recortes teórico-metodológicos: hábitos de consumo (Solomon, 2002); conhecimento dos produtos turísticos (Plummer, et al.,2005; Santos et al., 2014; Zhang et al., 2016); relação entre a cidade e o produto característico identitário (Azevedo et al., 2014; Gallarza et al., 2002; Lavandoski et al, 2012; Merrilees, Miller \& Herington, 2009; Pérez-Nebra, 2005; Plummer, et al. 2005); conhecimento dos produtos turísticos da cidade (Santos et al., 2014; Solomon, 2002; Zhang et al., 2016); e a presença em eventos identitários da cidade (Choo e Park, 2011; Gursoy et al., 2004; Zhang et al, 2016).

A coleta de dados ocorreu entre os dias 18 de maio a 9 de junho de 2015. A amostra da pesquisa foi composta por 400 residentes da cidade de Blumenau, com idade superior a 18 anos, que costumam beber cerveja ou chope artesanais com alguma frequência. Foi utilizada a técnica amostral "bola de neve", em que voluntários são escoIhidos e esses indicam "conhecidos" com o 
mesmo perfil, a fim de responderem entrevistas ou questionários. Essas indicações se dão de maneira sucessiva e formam redes de referência. A equipe de coleta de dados foi composta por 27 pesquisadores integrantes do Projeto Focus, da Universidade Regional de Blumenau.

Para alcançar tal amostra, os entrevistados foram, incialmente, submetidos a quatro perguntas filtro, foram elas: 1) Você bebe cerveja ou chope artesanais com alguma frequência? 2) Você reside em Blumenau? 3) Você tem 18 anos ou mais? 4) Qual a sua marca de cerveja/chope artesanais preferida? Foram excluídos da amostra, os entrevistados que responderam, negativamente, as três primeiras perguntas e que consideraram uma marca de cerveja comercial como se fosse uma marca de cerveja artesanal.

Para aplicar a verificação da confiabilidade e da consistência interna dos constructos, foi utilizado o Software Microsoft Excel para a codificação e tabulação dos dados. Posteriormente, para o tratamento e análises desses, foi utilizado o pacote estatístico Statistical Package for Social Science (SPSS). As análises estatísticas realizadas, foram descritivas e multivariadas. As primeiras foram utilizadas, essencialmente, com a finalidade de apresentar a frequência e a caracterização dos entrevistados.

Posteriormente, foi efetuada a Correlação de Spearman para avaliar a cultura cervejeira como identidade cultural de Blumenau. De de acordo com Hair, Black, Babin, Anderson, e Tatham (2009), o coeficiente apresentado na Correlação de Spearman, tipica- mente apresenta, como resultado, um coeficiente mais baixo. Todavia, ainda é considerado uma estatística mais conservadora. Justifica-se o uso dessa análise estatistica, pois é a mais indicada para os casos em que os dados não se ajustam a uma curva normal, ou seja, são não paramétricos, conforme apontado pelo teste de Kolmogorov-Smirnov, utilizado, previamente, nesse estudo ( $p<0,050$ em todas as variáveis).

O teste de hipóteses foi elaborado por meio de testes de Regressão Linear Múltiplas e investiga as possíveis relações causais, presentes nas hipóteses. A análise de Regressão Linear Múltiplas envolve a investigação, ao mesmo tempo, de diversas variáveis para explicar as relações existentes entre os dados. A técnica de estatística aplicada, permite determinar a validação, ou não, das hipóteses. Foram apresentados três conjuntos de modelos, um para cada variável dependente. Cada conjunto envolveu a relação entre uma variável dependente, com quatro variáveis independentes, com o teste de cada uma das quatro hipóteses traçadas.

A confiabilidade da consistência interna dos fatores identificados foi avaliada por meio do Alfa de Cronbach (Hair Jr. et al., 2009). O teste identificou um Alfa de Cronbach de 0,845, o que foi considerado aceitável para a validação da convergência do questionário. Com base nos parâmetros proposto por Cronbach (1951), valores acima de 0,70 são consideráveis aceitáveis para validação da convergência de instrumentos de coletas de dados. Todavia, Hair Jr. et al. (2009) definem que, em pesquisas com caráter explora- 
tório, o valor aceitável pode ser reduzido para 0,60 .

\section{DISCUSSÃO DOS RESULTADOS}

No que se refere a amostra da presente pesquisa, salienta-se que foi constituida por 400 residentes do municipio de Blumenau, Santa Catarina -SC. A amostra foi predominantemente masculina (63\%). Com referência à idade, a opção entre 18 e 25 anos (50\%) alcançou uma maior taxa de respostas, seguido por 26 e 35 anos (23\%) e 46 e 55 anos (12\%). No entnato, os residentes com mais de 56 anos de idade foram aqueles com a menor taxa de resposta (4\%). Em relação a renda média familiar dos respondentes, a ampla maioria afirmou receber entre $\mathrm{R} \$ 3.001,00$ a $\mathrm{R} \$ 5.000,00$ (23\%), seguidos por $\mathrm{R} \$ 5.001,00$ a $\mathrm{R} \$ 8.000,00$ (20\%), acima de $R \$ 8.000,00(21 \%)$ e, por fim, até $R \$$ $3.000,00$ (16\%).

Em relação a frequência de consumo de cerveja ou chope artesanais, os resultados indicam que a maioria do público da amostra bebe cerveja ou chope artesanais com uma frequência significativa. A maioria dos entrevistados afirmou que tem o costume de beber cerveja ou chope artesanais uma vez por semana (35\%). Na sequência, $25 \%$ afirmaram beber uma vez por mês e o consumo médio é de uma vez a cada 15 dias para $22 \%$ dos respondentes. Apenas $8 \%$ consomem cerveja e chope artesanais, a cada três meses ou menos. Por fim, $7 \%$ afirmam que bebem uma vez a cada dois meses.

Os entrevistados, de forma estimulada, informaram a marca artesanal que mais conhecem ou aquela da qual mais ouviram falar. Como exposto na Tabela 1 , o resultado indica que as marcas mais conhecidas foram a Eisenbahn (98\%), Bierland (95\%), Das Bier (93\%), Wunder Bier (86\%), Opa Bier (76\%). Logo em seguida, por ordem de número de respostas, estão as marcas Oktobier, Saint Bier e Borck, com mais de 200 indicações. Abaixo desse volume de citações, ficaram as demais marcas conhecidas, destacando-se, entre essas, a Schornstein com 195 indicações e a Zehn Bier com 189.

Os bebedores de cerveja e chope artesanais analisaram alguns dos principais aspectos da bebida, o que demonstrou a sua expertise sobre $\mathrm{o}$ assunto. A partir desse dado, a pesquisa procurou evidenciar quais as características mais analisadas pelos entrevistados, por meio de respostas "sim" ou "não", para oito afirmativas sobre os fatores determinantes para a qualidade do chope.

$\mathrm{O}$ aspecto da cor foi indicado como o mais analisado, (72\%); o aroma é observado por 296 respondentes (74\%); em seguida, a espuma é avaliada por $64 \%$ do total de entrevistados.

Quanto ao teor alcoólico, a análise é menos rigorosa, 196 pesquisados (49\%) revelam que analisam essa característica. A origem/procedência é avaliada como fator determinante por metade dos participantes da pesquisa (50\%). O rótulo é levado em consideração por $64 \%$ dos entrevistados, mas os ingredientes parecem importar menos, pois menos da metade avaliam esse aspecto, são $42 \%$. Menos avaliados ainda, foram os valores nutricionais, que receberam apenas 32 
respostas positivas, indicando $8 \%$. Os resultados indicam que os bebedores de cerveja são exigentes com a bebida, pois cinco, dos oito aspectos, são considerados importantes por, pelo menos, $50 \%$ dos entrevistados.

Tabela 1 - Marcas de chope regionais conhecidas pelos residentes de Blumenau (SC)

\begin{tabular}{|c|c|c|}
\hline \multirow{2}{*}{ Marcas } & \multicolumn{2}{|c|}{ Conhece } \\
\hline & Frequência & Porcentagem \\
\hline Eisenbahn & 393 & $98 \%$ \\
\hline Bierland & 381 & $95 \%$ \\
\hline Das Bier & 371 & $93 \%$ \\
\hline Wunder Bier & 344 & $86 \%$ \\
\hline Opa Bier & 304 & $76 \%$ \\
\hline Oktobier & 245 & $61 \%$ \\
\hline Saint Bier & 217 & $54 \%$ \\
\hline Borck & 204 & $51 \%$ \\
\hline Schornstein & 195 & $49 \%$ \\
\hline Zehn Bier & 189 & $47 \%$ \\
\hline Container & 149 & $37 \%$ \\
\hline Heimat & 88 & $22 \%$ \\
\hline Königs Bier & 74 & $18 \%$ \\
\hline Handwerk & 69 & $17 \%$ \\
\hline Volksbier & 66 & $16 \%$ \\
\hline
\end{tabular}

Fonte: Dados do projeto Focus (2015)

Quando inquerido, em relação ao produto turistico de Blumenau relacionado com a cultura cervejeira, os entrevistados foram questionados se conhecem ou já ouviram falar da Rota das Cervejarias Artesanais, do Museu da Cerveja e das principais Cervejarias de Blumenau e região. Os resultados apontam que a maioria dos respondentes possui apenas o conhecimento acerca da existência de tais produtos turísticos (54\%), $31 \%$ dos residentes não conhecem ou nunca ouviram falar e, somente, 52 pesquisados (representando 13\%) conhecem e já percorreram a Rota. Os entrevistados que não souberam dizer, ou não lembram, representam $2 \%$. Com os resultados, é possível concluir que a maioria dos apreciadores de cerveja e chope artesanais conhece os produtos turísticos da cidade de Blumenau, porém não frequenta tais locais.

A identificação do residente com o consumo de cerveja e chope artesanais foi 
avaliada por meio de duas variáveis, com quatro opções de respostas: concordo totalmente, concordo em parte, discordo e não sei dizer. Em relação aos preços praticados pela maioria das cervejarias artesanais da região de Blumenau, 196 residentes (49\%) concordaram, em parte, que eles são compatíveis com a qualidade de seus produtos; 171 (43\%) concordaram totalmente e 29 (7\%) discordaram. Dos 400 respondentes, a maioria, equivalente a $58 \%$, concordou, totalmente, com a afirmação de que, comparadas com as cervejas de grandes marcas, as cervejas artesanais têm qualidade, indiscutivelmente, superior. Os entrevistados que concordaram, em parte, somam 119 (30\%) e os que discordaram, são 36 respondentes (9\%), os demais não souberam responder.

Com relação à acertativa "a relação do destino Blumenau com a cerveja artesanal", a ampla maioria dos respodentes afirmou que concorda totalmente (83\%); $15 \%$ concordaram, porém em parte; apenas, $1 \%$ discordaram; e os demais não souberam dizer. A maioria (67\%) concordou, totalmente, que Blumenau e região se destacam, nacionalmente, na produção de cervejas artesanais; $25 \%$ concordaram em parte; contra apenas $4 \%$ que discordaram. Os outros $5 \%$ não souberam dizer.

No que diz respeito ao conhecimento dos produtos turísticos e a expertise, também estão correlacionados positivamente $\left(0,116^{*}\right)$, o que indica que quanto mais as pessoas conhecem os produtos turísticos de Blumenau, tanto maior será a expertise delas sobre cerveja e chope artesanais. De outro modo, a identificação com a cerveja e chope artesanais está relacionada, positivamente, à frequência do seu consumo $\left(0,108^{*}\right)$, ao número de marcas regionais conhecidas $\left(0,107^{*}\right)$ e à expertise sobre cerveja e chope artesanais $\left(0,231^{* *}\right)$, ou seja, existe uma correlação entre essas variáveis e indica que quanto maior a identificação do indivíduo com cerveja ou chope artesanais, maior será a frequência de consumo deles, maior será o número de marcas regionais que conhecem e maior ainda é sua expertise sobre cerveja e chope artesanais.

Quando se afirmou que Blumenau é a cidade da cerveja artesanal, $40 \%$ dos entrevistados concordaram em parte; $37 \%$ concordaram totalmente; os que discordaram somam $14 \%$; e $9 \%$ não souberam dizer. No tocante ao blumenauense se identificar com as festas que têm como tema a cerveja, a maioria, representada por $77 \%$ do total de entrevistados, concordou totalmente com essa afirmação e $20 \%$ concordaram em parte. Somente $2 \%$ discordaram.

Com o intuito de identificar o interesse dos residentes por atividades e eventos relacionados à cerveja e à cultura germânica no municipio de Blumenau, os respondentes foram convidados a demonstrar a sua frequência de participação em cinco eventos locais, relacionados com a temática (Tabela 2). 
Tabela 2 - Frequência da presença em eventos de cerveja na cidade

\begin{tabular}{|c|c|c|c|c|c|c|}
\hline \multirow{2}{*}{ Evento } & \multicolumn{2}{|c|}{ Sim } & \multicolumn{2}{|c|}{ Não } & \multicolumn{2}{|c|}{ Total } \\
\hline & Freq. & $\%$ & Freq. & $\%$ & Freq. & $\%$ \\
\hline Oktoberfest & 380 & $95 \%$ & 20 & $5 \%$ & 400 & $100 \%$ \\
\hline Bailes do Chopp & 84 & $21 \%$ & 316 & $79 \%$ & 400 & $100 \%$ \\
\hline Sommerfest & 312 & $78 \%$ & 88 & $22 \%$ & 400 & $100 \%$ \\
\hline Stammtisch & 276 & $69 \%$ & 124 & $31 \%$ & 400 & $100 \%$ \\
\hline Festival de Botecos & 244 & $61 \%$ & 156 & $39 \%$ & 400 & $100 \%$ \\
\hline
\end{tabular}

Fonte: Dados do projeto Focus (2015)

Referente à Oktoberfest, a maioria dos entrevistados (95\%) afirmou participar da programação; um considerável número de residentes (78\%) também afirmou frequentar a Sommerfest. Em seguida, uma menor parcela de entrevistados afirmou que frequenta o Stammtisch (69\%). O Festival de Botecos aparece em quarto lugar, como o evento mais frequentado pelos entrevistados (61\%) e os Bailes de Chopp aparecem com a menor participação, nos quais somente $21 \%$ dos residentes afirmaram frequentar 0 evento.

Para a avaliação da correlação entre as variáveis apresentadas, foi aplicado a análise estatistica Correlação de Spearman. Os resultados alcançados pela análise, conforme exposto na Tabela 3, demonstraram, primeiramente, que a expertise sobre cerveja e chope artesanais está, positivamente, correlacionada com as variáveis de frequência de consumo de cerveja ou chope artesanais $\left(0,162^{* *}\right)$ e o número de marcas regionais conhecidas $\left(0,110^{*}\right)$. Essa correlação indica que quanto mais o indivíduo possui expertise sobre cerveja e chope artesanais, tanto maior será sua frequência de consumo de cerveja ou chope artesanais e tanto maior será o número de marcas regionais que conhece. 
Tabela 3 - Correlação de Spearman

\begin{tabular}{|c|c|c|c|c|c|c|c|c|c|c|}
\hline & $\begin{array}{l}\text { Freq. de con- } \\
\text { sumo de cer- } \\
\text { veja e chope } \\
\text { artesanal }\end{array}$ & $\begin{array}{l}\text { № de marcas } \\
\text { regionais que } \\
\text { conhece }\end{array}$ & $\begin{array}{l}\text { Expertise: cer- } \\
\text { veja e chope } \\
\text { artesanal }\end{array}$ & $\begin{array}{l}\text { Conhece os pro- } \\
\text { dutos turísticos }\end{array}$ & $\begin{array}{l}\text { Identificação com } \\
\text { cerveja e chope ar- } \\
\text { tesanal }\end{array}$ & $\begin{array}{l}\text { Relação entre Blume- } \\
\text { nau e cerveja ou } \\
\text { chope artesanal }\end{array}$ & $\begin{array}{l}\text { Presença em } \\
\text { eventos de } \\
\text { cerveja na ci- } \\
\text { dade }\end{array}$ & Gênero $(H)$ & Idade & Renda \\
\hline $\begin{array}{l}\text { Freq. de consumo de } \\
\text { cerveja e chope artesa- } \\
\text { nal }\end{array}$ & 1,000 & & & & & & & & & \\
\hline $\begin{array}{l}\text { № de marcas regionais } \\
\text { que conhece }\end{array}$ & 0,011 & 1,000 & & & & & & & & \\
\hline $\begin{array}{l}\text { Expertise: cerveja e } \\
\text { chope artesanal }\end{array}$ & $0,162^{* *}$ & $0,110^{*}$ & 1,000 & & & & & & & \\
\hline $\begin{array}{l}\text { Conhece os produtos } \\
\text { turísticos }\end{array}$ & 0,055 & 0,018 & $0,116^{*}$ & 1,000 & & & & & & \\
\hline $\begin{array}{l}\text { Identif. com cerveja e } \\
\text { chope artesanal }\end{array}$ & $0,108^{*}$ & $0,107^{*}$ & $0,231^{* *}$ & 0,076 & 1,000 & & & & & \\
\hline $\begin{array}{l}\text { Relação entre Blume- } \\
\text { nau e cerveja ou chope } \\
\text { artesanal }\end{array}$ & $0,138^{* *}$ & 0,003 & $0,114^{*}$ & 0,064 & $0,266^{* *}$ & 1,000 & & & & \\
\hline $\begin{array}{l}\text { Presença em eventos } \\
\text { de cerveja na cidade }\end{array}$ & $0,270^{* *}$ & $-0,017$ & $0,110^{*}$ & $0,316^{* *}$ & $0,133^{* *}$ & $0,170^{* *}$ & 1,000 & & & \\
\hline Gênero (H) & 0,085 & 0,093 & 0,086 & $-0,005$ & $-0,043$ & 0,045 & 0,038 & 1,000 & & \\
\hline Idade & 0,072 & 0,061 & $0,149^{* *}$ & $0,150^{* *}$ & 0,087 & 0,032 & 0,030 & 0,015 & 1,000 & \\
\hline Renda & 0,039 & 0,084 & $-0,016$ & 0,044 & 0,051 & 0,037 & 0,014 & $-0,014$ & $0,202^{* *}$ & 1,000 \\
\hline
\end{tabular}

Fonte: Dados da pesquisa do Projeto Focus (2015) 
A correlação de Spearman demonstrou, ainda, que existe uma correlação positiva entre a variável da relação Blumenau e cerveja e chope artesanais e as variáveis de frequência de consumo $\left(0,138^{* *}\right)$, expertise $\left(0,114^{*}\right)$ e, principalmente, com a variável de identificação com cerveja e chope artesanais $\left(0,266^{* *}\right)$. Essa correlação determina que quanto mais as pessoas compreendem a relação entre Blumenau, cerveja e chope artesanais, maior será a frequência de consumo do produto característico, maior será a expertise sobre cerveja e chope artesanais e maior ainda é a identificação com o produto característico.

A presença em eventos de cerveja em Blumenau, por sua vez, está positivamente correlacionada com as variáveis de frequência de consumo $\left(0,270^{* *}\right)$, expertise $\left(0,110^{*}\right)$, conhecimento dos produtos turísti$\cos \left(0,316^{* *}\right)$, identificação $\left(0,133^{* *}\right)$ e relação da cidade com cerveja e chope artesanais $(0,170 * *)$. Esse resultado revela que quanto mais as pessoas estão presentes nos eventos de cerveja da cidade de Blumenau, maior será a sua frequência do consumo de cerveja e chope artesanais. Quanto mais presentes em eventos de cerveja na cidade maior também é a sua expertise, ou seja, mais elas avaliam e conhecem as características da cerveja e do chope artesanais e, maior ainda é o seu conhecimento dos produtos turísticos. Esse se destaca por ter um resultado, positivamente, maior que as demais variáveis. Constata-se também que quanto maior a presença em eventos, maior será a identificação com cerveja e chope artesanais e maior será a relação percebida pelos residentes entre Blumenau e produto característico.

Com base na pesquisa exploratória, foram desenvolvidas doze hipóteses, sustentadas nas teorias apresentadas ao longo desse estudo. Uma hipótese é considerara por Hair Jr. et al.(2009), como uma suposição ou proposição não comprovada que tenta explicar certos fatos ou fenômenos. As hipósteses, em questão, são caracterizadas como hipóteses direcionais que estabelecem uma relação entre dois grupos ou variáveis. Fundamentada na discussão anterior, a Figura 2 apresenta as doze hipóteses elaboradas que foram testadas no presente estudo.

Figura 2 - Modelo conceitual de estudo VI 1

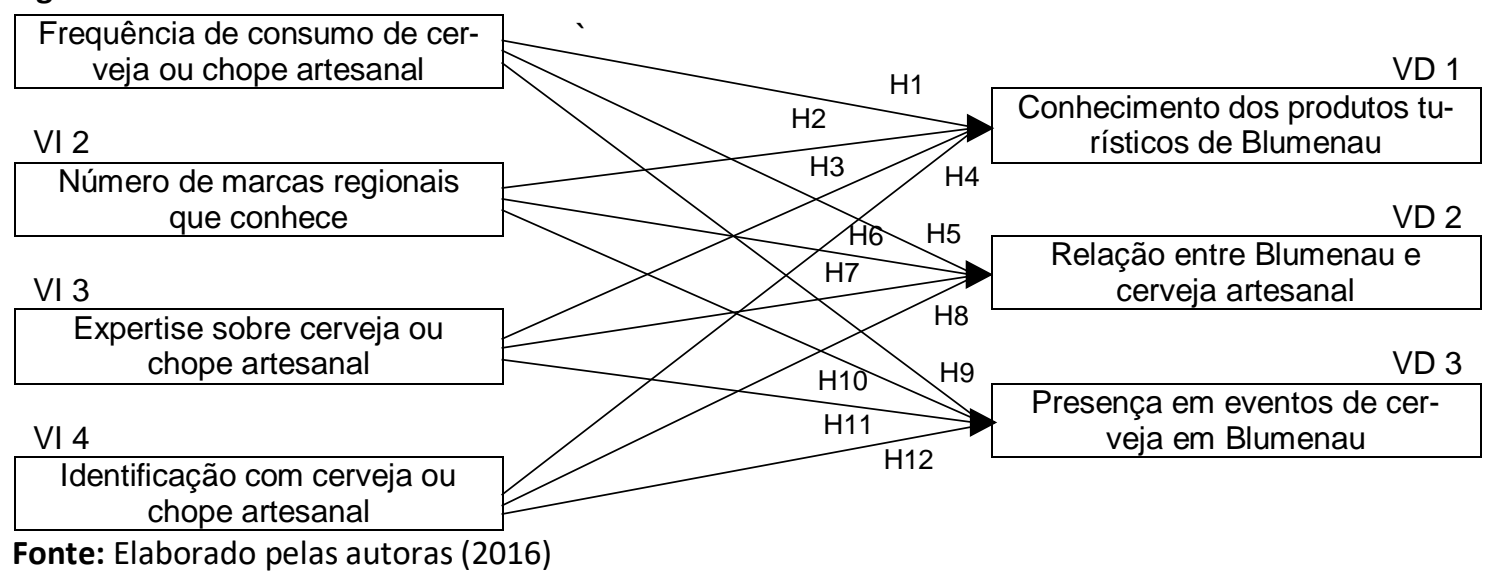

Rev. Bras. Pesq. Tur. São Paulo, 11(2), pp. 320-346, maio/ago. 2017. 
A Tabela 4 apresenta o primeiro conjunto de hipóteses testadas, baseadas na relação entre a variável dependente do conhecimento dos produtos turísticos e as variáveis independentes. Os resultados indicam que apenas a hipótese 3 foi confirmada, a qual afirma que quanto maior a expertise do residente sobre cerveja e chope artesanais, mais ele conhece os produtos turísticos da cidade. Ou seja, maior será o seu conhecimento no tocante aos produtos turísticos de Blumenau.

Tabela 4 - Teste de hipóteses para a variável do conjunto turístico

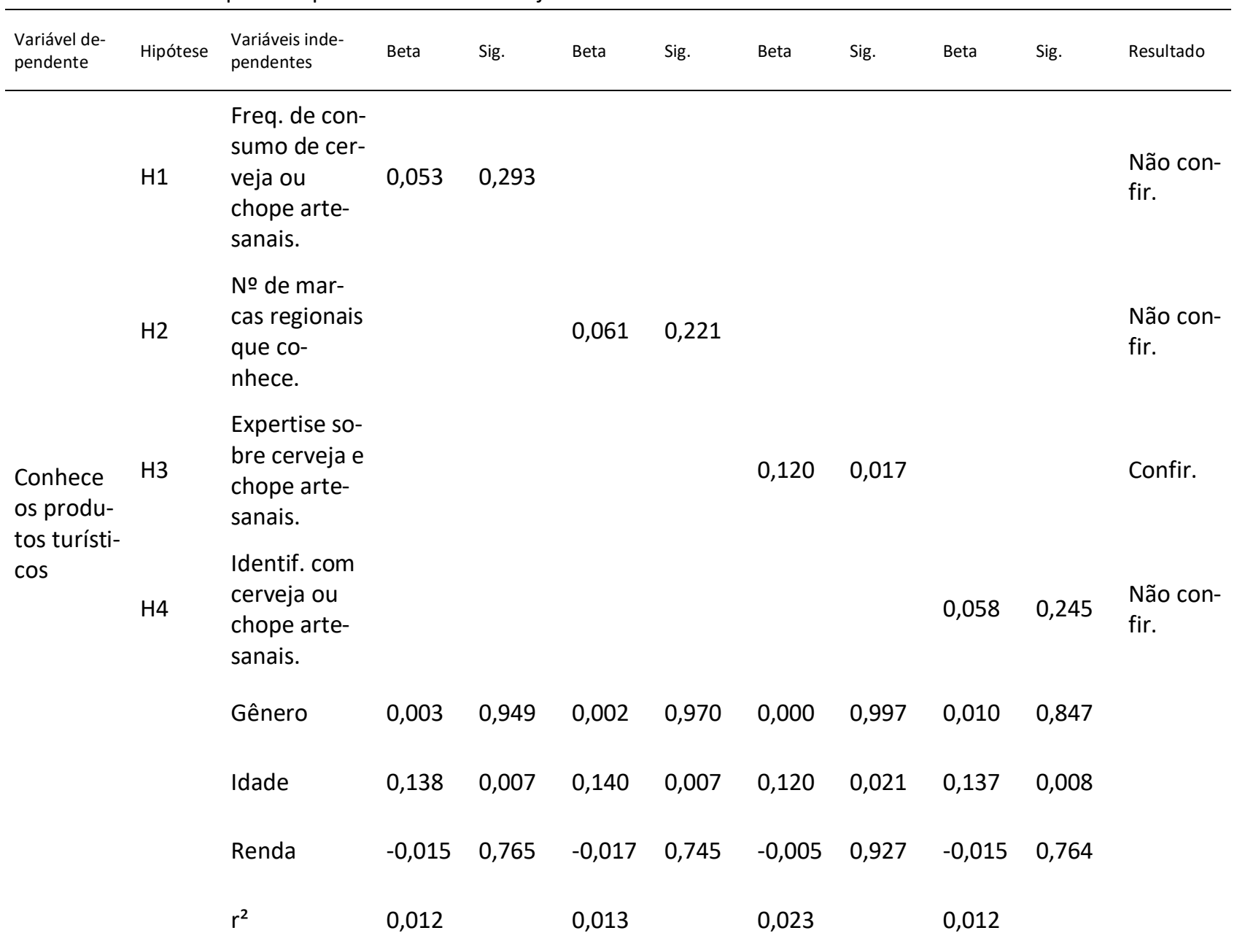

Nota: foi adotado um alfa de 95\% para indicar significância, o que sugere um p-valor menor que 0,05 para considerar uma relação significante.

Fonte: Elaborado pelas autoras (2016).

Embora estejam apoiadas nos estudos de Santos et al. (2014), Pérez-Nebra (2005) e Plummer et al. (2005), com os quais foi possível compreender que os residentes, além da culinária e da bebida, são parte integrante do caráter intrínseco do produto turís- tico; apenas uma das hipóteses foi validada. Assim, é possível reafirmar, na realidade desse estudo, que o conhecimento do residente sobre chope e cerveja artesanais é significante para que haja conhecimento dos produtos turísticos dacidade. Outras carac- 
terísticas presentes nos hábitos dos residentes, como a frequência de consumo de cerveja ou chope artesanais, número de marcas que conhece e identificação com cerveja ou chope artesanais; não apresentaram resultados relevantes para indicar a existência de uma correlação positiva com o conhecimento dos produtos turísticos.

É possível verificar uma relação com a teoria colocada por Santos et al. (2014), em que afirmam que o cenário turístico é composto por atrativos turísticos e que seu desenvolvimento é influenciado pelas características do próprio destino. Nesse caso, o residente que reconhece as características específicas da cerveja ou chope artesanais tem um conhecimento maior sobre os produtos turísticos da cidade, visto que esses estão relacionados à cerveja e ao chope artesanais.

Existe, ademais, uma relação com as colocações de Plummer et al. (2005) que afirmam que os locais de produção dos produtos característicos do destino podem ser vistos como atrativos turísticos de uma região. $\mathrm{O}$ indivíduo que visita esses locais cria a consciência da marca do destino e da imagem de qualidade que ele possui. Ao se transportar essas afirmações para a realidade de Blumenau, pode-se destacar a Rota das Cervejas que inclui, além do Museu da Cerveja, as cervejarias onde se fabricam cervejas e chopes artesanais.

Assim, se o blumenauense conhece os produtos turísticos, ele cria a consciência da imagem e identidade de Blumenau. É válido destacar que Zhang et al. (2016) consideram importante a presença dos residentes nos locais, para transmitir autenticidade para a atividade turística, bem como a influência que o local tem sobre a vida dos residentes, quando atua como opção de lazer e depósito cultural.

A Tabela 5 apresenta o segundo conjunto de hipóteses testadas, baseadas na relação entre a variável dependente da relação entre Blumenau e cerveja artesanal e as variáveis independentes. Os resultados indicam que apenas a hipótese 6 não foi confirmada, a qual afirma que quanto maior o número de marcas regionais conhecidas de cerveja e chope artesanais, maior será a percepção do residente da relação entre Blumenau e cerveja artesanal. Portanto, o número de marcas conhecidas pelo blumenauense não influencia na sua percepção sobre a relação entre Blumenau, cerveja e chope artesanais.

As demais hipóteses desse conjunto (Tabela 5) foram suportadas pelos resultados e indicam que quanto maior frequência de consumo, a expertise e a identificação com cerveja ou chope artesanais, maior será a relação entre Blumenau e cerveja artesanal percebida pelo residente. Nesse caso, existe uma semelhança entre os aspectos estudados e as colocações de Azevedo, Paes e Andrade (2014), pois as práticas e bens culturais que identificam os residentes passam a identificar o destino. 
Tabela 5 - Teste de hipóteses para a variável da relação entre Blumenau e cerveja artesanal

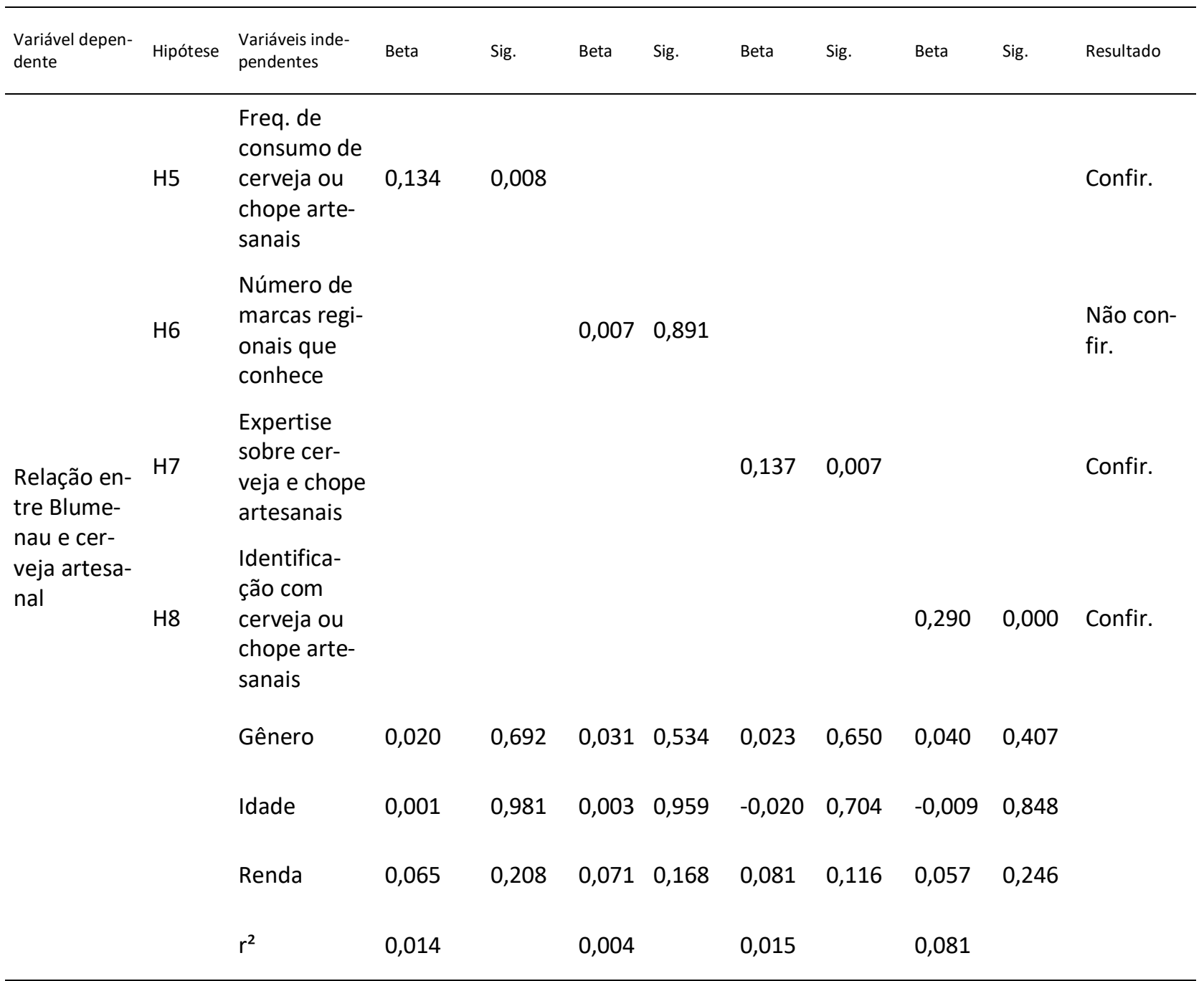

Nota: foi adotado um alfa de $95 \%$ para indicar significância, o que sugere um $p$-valor menor que 0,05 para considerar uma relação significante.

Fonte: Elaborado pelas autoras (2016).

A percepção do residente, em torno de objetos ou destinos, com relação a determinados atributos ou características, é uma dimensão que relaciona as variáveis para a medição da imagem, de acordo com Gallarza, Saura e García (2002). Portanto, a observação dos hábitos de frequência de consumo, expertise e identificação mostra a existência da relação entre o produto característico e Blumenau, logo sua imagem passa a englobar essa relação. A teoria de Merrilees, Miller,
Herington (2009) também está relacionada com os resultados desse conjunto, posto que em seu estudo, os autores afirmam que, com base nas percepções dos residentes, é possível atribuir características ao destino que, geralmente, estão relacionadas à cultura, ao patrimônio ou às atividades culturais.

Por fim, a Tabela 6 apresenta o terceiro conjunto de hipóteses testadas, baseadas na relação entre a variável dependente da presença em eventos de cerveja na cidade 
e as variáveis independentes. Os resultados indicam que apenas a hipótese 10 não foi confirmada, a qual afirma que quanto maior o número de marcas regionais conhecidas, maior será a presença em eventos turísticos da cidade. Portanto, o número de marcas regionais de cerveja e chope artesais que o blumenauense conhece, não possui grande influência na sua presença em eventos de cerveja em Blumenau.

As demais hipóteses desse conjunto foram suportadas pelos resultados, conforme exposto na Tabela 6 e indicam que quanto maior a frequência de consumo, a expertise e a identificação com cerveja ou chope artesanais, maior será a presença de residentes em eventos turísticos da cidade. É possível identificar uma proximidade com os resultados de Choo e Park (2011); Gursoy, Kim, Uysal, (2004) e Zhang et al. (2016). Assim como no presente estudo, Choo e Park (2011) constataram que quanto mais o residente se identifica com a marca do destino, mais eles desfrutam das atividades de turismo e lazer do seu lugar.

Tabela 6 - Teste de hipóteses para a variável da presença em eventos de cerveja em Blumenau

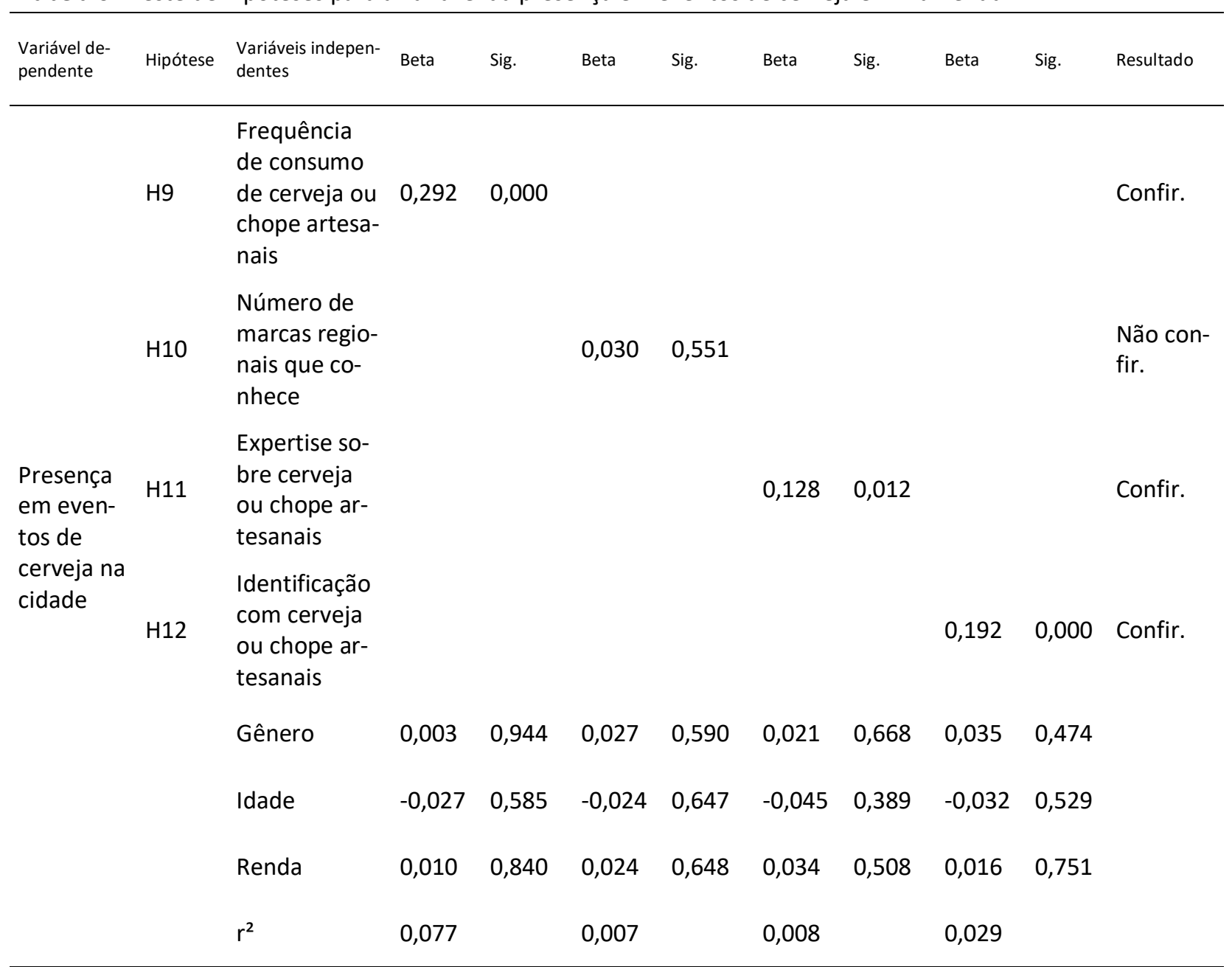

Nota: foi adotado um alfa de 95\% para indicar significância, o que sugere um p-valor menor que 0,05 para considerar uma relação significante.

Fonte: Elaborado pelas autoras (2016). 
No presente estudo, a relação entre marca e identidade também é existente, pois quanto mais o blumenauense se identifica com chope e cerveja artesanais, maior será a presença dele em eventos de cerveja na cidade. Para Zhang et al. (2016), a participação do residente em eventos desse porte, reforça a identidade e a cultura do destino, pois os festivais e eventos estão ligados ao compartilhamento de cultura e demonstram, de forma simbólica, o que integra a sociedade em que se celebra. Zhang et al. (2016) afirmam, ainda, que eventos assim se enquadram em opções de lazer, diversão e depósito cultural para os residentes.

No contexto da propaganda e da promoção turística, é necessário que ambas atuem como estratégias eficazes e demonstrem fidelidade ao posicionamento e imagem do destino (Buosi et al., 2017). Além da importância de desenvolver constantemente a marca do destino, ela deve estar ralacionada com a identidade do lugar. A cultura e as características próprias de um destino agem como elementos identificadores e úteis para a propaganda dentro das ações de marketing.

\section{CONCLUSÕES E RECOMENDAÇÕES}

O presente trabalho teve o objetivo de analisar, a partir das atitudes dos residentes, a cultura cervejeira como identidade cultural de Blumenau, para a promoção turística da cidade. Por meio da pesquisa, obtiveramse variáveis com as quais foi possível realizar testes de correlação para identificar as relações existentes entre elas. Diante das correlações, o teste de hipóteses verificou a vali- dação das suposições propostas, com base na revisão de literatura. A revisão de literatura expõe: a teoria de troca social, o processo de formação de imagem de destino, a participação do residente e de como o turismo afeta sua percepção. Em contrapartida, esse estudo demonstra uma nova perspectiva.

Em resumo, os fundamentos teóricos são vistos como teorias que contribuíram para esse estudo, a fim de oferecer uma nova perspectiva: a identificação e a proximidade do residente com a cultura cervejeira, no intuito de transformar a cerveja e o chope artesais na identidade de Blumenau e, consequentemente, em seus fomentadores turísticos.

Ao averiguar os resultados do teste de hipóteses, em que sete das doze hipóteses foram confirmadas, contatou-se que a cultura cervejeira está presente na identidade da cidade de Blumenau, diante das atitudes e identificação do residente. Ao mesmo tempo em que o residente consome cerveja e chope artesais, ele tem conhecimento acerca desse assunto e se identifica. Além de enxergar a importância das cervejarias, como produto turístico para Blumenau, o residente está presente nas festas de cerveja e considera essa imagem adequada para a cidade.

Foi possível compreender as variáveis conceituais que compõem o comportamento do blumenauense, em relação à cultura cervejeira. Algumas variáveis influenciam mais do que outras, na identificação da identidade cultural de Blumenau. Porém, mesmo que os residentes possuam hábitos positivos em relação à cultura cervejeira, eles desconhecem os produtos turísticos de sua cidade. Somen- 
te aqueles que possuem expertise sobre o assunto, têm o conhecimento sobre os produtos turísticos. Desse modo, percebe-se a necessidade de qualificar os planejamentos de propaganda dos atrativos da cidade, para assim, ganhar visibilidade dos residentes. Por outro lado, os seus hábitos fazem com que a relação entre Blumenau e cerveja artesanal seja mais forte, bem como sua presença em eventos de cerveja, sem que seja primordial o conhecimento de todas as marcas regionais. A forte presença em eventos é um ponto positivo para que a diversidade de cervejearias, tipos de cervejas e chope sejam expostos e conquistem um espaço no conhecimento do residente.

No que tange à identificação da relação entre hábitos e costumes do residente e o conhecimento sobre os produtos turísticos da cidade de Blumenau, esse estudo confirmou apenas uma das quatro hipóteses desse conjunto, em que afirma: quanto maior a expertise do residente pelo produto característico da cidade, mais ele conhecerá os produtos turísticos da cidade, ou seja, quanto maior a expertise do blumenauense sobre cerveja e chope artesais, maior será o conhecimento dele sobre os produtos turísticos da cidade.

Ao identificar a percepção do residente sobre a relação entre Blumenau e cerveja e chope artesais, os dados indicam resultados positivos para três de quatro hipóteses desse conjunto, em que apenas uma não foi confirmada. As demais hipóteses desse conjunto foram suportadas pelos resultados e indicaram: quanto maior a frequência de consumo, a expertise e a identificação com cer- veja ou chope artesanais, maior será a relação, percebida pelo residente, entre Blumenau e cerveja artesanal.

Ao identificar a relação entre os hábitos e os costumes do residente e a presença em eventos turísticos de Blumenau, os resultados também foram positivos para três de quatro hipóteses desse conjunto. Apenas uma hipótese não foi confirmada, a qual afirma que quanto maior o número de marcas regionais de cerveja e chope artesanais conhecidas pelo residente, maior será a presença em eventos turísticos da cidade. Portanto, o número de marcas regionais que o blumenauense conhece, não possui grande influência na sua presença em eventos de cerveja em Blumenau. As demais hipóteses desse conjunto foram suportadas pelos resultados e indicaram: quanto maior a frequência de consumo, a expertise e a identificação com cerveja ou chope artesanais, maior será a presença de residentes em eventos turísticos da cidade.

Especificamente, os dados foram coletados de residentes de Blumenau que consomem cerveja ou chope artesanais. Dessa maneira, é provável que eles tenham respondido as perguntas do questionário, com base em suas experiências em Blumenau. Portanto, os resultados desse estudo não podem ser generalizados, para além da amostra examinada. Estudos futuros, com amostras maiores em locais diferentes, podem ser utilizados para comprovar hipótese e adaptados para diferentes destinos. Pesquisadores futuros também podem considerar a incorporação de outras dimensões da identidade, relevantes para a sua área de estudo, como a 
percepção do turísta, por exemplo. Outra sugestão é a adaptação das hipóteses para outros destinos. Apesar das limitações acima, o estudo faz algumas contribuições teóricas úteis à literatura.

\section{REFERÊNCIAS}

Andereck, K. L., Valentine, K. M., Knopf, R. C., \& Vogt, C. A. (2005). Residents' perceptions of community tourism impacts. Annals of tourism research, 32(4), 1056-1076.

Azambuja, V. A., \& Mecca, M. S. (2017). Os componentes da identidade de marca de Gramado/Brasil que geram sua imagem de "destino turístico modelo" e os relacionamentos da marca com os stakeholders internos. Revista Brasileira de Pesquisa em Turismo, 11(1), 1-18.

Azevedo, D. S., Paes, T. A., \& Andrade, P. B. (2014) Reflexões sobre as identidades-consumo na América Latina sobre a ótica da atividade turística. Ambivalências: Revista do Grupo de Estudos e Pesquisa Processos Identitários e Poder, 2(3), $218-237$.

Banducci Júnior, Á.; Barretto, M. (2001) Turismo e identidade local: uma visão antropológica. $\mathrm{Pa}$ pirus, Campinas.

Besculides, A., Lee, M. E., \& Mccormick, P. J. (2002) Residents' perceptions of the cultural benefits of tourism. Annals of tourism research, 29(2), 303-319.

Brasil, Ministério do Turismo (2015) Anuário Estatístico 2015: Ano Base 2014. Recuperado em 02 mar. 2016, de http://www.dadosefatos.turismo.gov.br/export/sites/default/dadosefa- tos/anuario/downloads anuario/Anuario Estatistico Turismo 2015 Ano base 2014 Divulgacao 2.pdf.

Buosi, M. C. de A., Lima, S. H. de O., \& Silva, Á. L. L. da (2017) Relación entre la percepción del desarrollo sustentable y la imagen del lugar según los residentes de un destino de turismo internacional. Estudios y perspectivas en turismo, 26(1), 128-149.

Carniello, M. F. \& Santaella, L. (2012) Imagem turística de São Sebastião (SP). Caderno Virtual de Turismo 12(3), 287-308.

Choo, H. \& Park, S. (2011) The influence of the resident's identification with a tourism destination brand on their behavior. Journal of Hospitality Marketing \& Management 20(2), 198-216.

Dias, R. \& Cassar, M. (2006) Fundamentos do marketing turístico. Person Prentice Hall, São Paulo.

Echtner $_{2}$ C. M. \& Ritchie, J.R. B. (1991) The meaning and measurement of destination image. The Journal of Tourism Studies 2(2), 2-12.

Fernandes, D. F., Lacay, M. A. C., \& Gândara, J. M. G. (2016) La influencia de la seguridad pública en la satisfacción y en la formación de la imagen de Curitiba (Brasil) para el visitante y los visitados. Estudios y perspectivas en turismo, 25(4), 416438.

Gallarza, M. G., Saura, I. G., \& García, H. C. (2002) Destination image: Towards a conceptual framework. Annals of tourism research, 29(1), 5678.

Gursoy, D., Kim, K., \& Uysal, M. (2004) Perceived 
impacts of festivals and special events by organizers: an extension and validation. Tourism management, 25(2), 171-181.

Hair, J. F., Black, W. C., Babin, B. J., Anderson, R. E., \& Tatham, R. L. (2009) Análise multivariada de dados. Bookman Editora, Porto Alegre.

Jackson, L. A. (2008) Residents' perceptions of the impacts of special event tourism. Journal of Place Management and development 1(3), 240-255.

Lavandoski, J., Tonini, H., \& Barreto, Margarita (2012) Uva, vinho e identidade cultural da Serra Gaúcha (RS, Brasil). Revista Brasileira de Pesquisa em Turismo 6(2), 216-232.

Mazzon, J. A., \& Vera, L. A. N. (2008) A opinião dos turistas de negócios sobre a Imagem da Cidade de São Paulo. Revista Turismo em Análise, 19(3), 345-368.

Merrilees, B., Miller, D., \& Herington, C. (2009) Antecedents of residents' city brand attitudes. Journal of Business Research, 62(3), 362-367.

Miranda, R. L. \& Miranda, R. De A. (1999) Marketing voltado para o turismo. APMS Books, São Paulo.

Neiman, Z., Geerdink, S., \& Pereira, J. C. (2011) A imagem como agente motivador para o ecoturismo. Revista Turismo em Análise, 22(1), 71-95.

Neto, V. (2015) Turismo contribui com $9 \%$ do PIB mundial. EMBRATUR. Recuperado em 02 mar. 2016, de http://www.embratur.gov.br/piembratur-new/opencms/salalmprensa/artigos/arquivos/Turismo contribui com 9 do PIB mundial.html.

Nunkoo, R. \& Gursoy, D. (2012) Residents' support for tourism: An identity perspective. Annals of Tourism Research 39(1), 243-268.
Pérez-Nebra, A. R. (2005) Medindo a imagem do destino turístico. Dissertação (mestrado) - Universidade Federal de Brasília, Brasília, Brasil.

Pérez-Nebra, A. R. \& Rosa, C. J. (2008) As novas estratégias de promoção do Brasil no exterior: estudo de caso. Revista Turismo em Análise, 19(3), 450-471.

Plummer, R., Telfer, D., Hashimoto, A., \& Summers, R. (2005) Beer tourism in Canada along the Waterloo-Wellington ale trail. Tourism Management, 26(3), 447-458.

Prefeitura Municipal de Blumenau (2015) Plano Municipal de Turismo de Blumenau. Recuperado em 22 mar. 2016 de http://www.blumenau.sc.gov.br/downloads/sectur/pmt.pdf.

Samara, B. S.; Barros, J. C. de. (2002) Pesquisa de marketing: conceitos e metodologia Pearson/Ptentice Hall, São Paulo.

Santos, M. M., Ferreira, A. M., \& Costa, C. (2014) Identificação dos recursos nucleares do destino como suporte para o desenvolvimento de produtos turísticos inovadores. Revista Turismo \& Desenvolvimento, 21(4), 315-330.

Silva, G. B., \& Junior, S. M. (2016). Fatores que afetam o apoio dos residentes para o desenvolvimento do turismo religioso: o caso de Santa Cruz (RN), Brasil. Revista Brasileira de Pesquisa em Turismo, 10(3), 497-515.

Solomon, M. R. (2002) Comportamento do consumidor: comprando, possuindo e sendo. 5a ed. Porto Alegre: Bookman.

Stets, J. E. \& Biga, C. F. (2003) Bringing identity theory into environmental sociology. Sociological Theory 21(4), 398-423. 
Wang, S., \& Chen, J. S. (2015) . The influence of place identity on perceived tourism impacts. Annals of Tourism Research, 52, 16-28.

Williams, D. R., McDonald, C. D., Riden, C. M., \& Uysal, M. (1995) Community attachment, regional identity and resident attitudes toward tourism. In: Annual Travel And Tourism Research Association Conference Proceedings, 424-428.

Williams, P. W., \& Kelly, J. (2001) Cultural wine tourists: Product development considerations for British Columbia's resident wine tourism market, International Journal of Wine Marketing, 13(3), 59-76.

Zhang, X., Ryan, C., \& Cave, J. (2016) Residents, their use of a tourist facility and contribution to tourist ambience: Narratives from a film tourism site in Beijing. Tourism Management, 52, 416429.

Dados dos Autores

\section{Fabricia Durieux Zucco}

Doutora em Administração pela Universidade Nove de Julho (UNINOVE). Mestre em Administração pela Universidade Regional de Blumenau (FURB). Especialista em Marketing pela Universidade Regional de Blume- nau (FURB). Bacharel em Publicidade e Propaganda pela Universidade Regional de Blumenau (FURB). Professora do Programa de Mestrado e Doutorado em Turismo da Universidade do Vale do Itajaí (UNIVALI). Professora do Departamento de Comunicação da Universidade Regional de Blumenau (FURB). Email: fabriciazucco@hotmail.com

\section{Cynthia Morgana Boos de Quadros}

Doutora em Desenvolvimento Regional pela Universidade Regional de Blumenau (FURB). Mestre em Ciências da Linguagem pela Universidade do Sul de Santa Catarina (UNISUL). Bacharel em Publicidade e Propaganda pela pela Universidade Regional de Blumenau (FURB). Professora do Departamento de Comunicação da Universidade Regional de Blumenau (FURB). Email: cynthiadequadros@gmail.com

\section{Juliane Regina Schmitt}

Pesquisadora em Comunicação. Bacharel em Publicidade e Propaganda pela Universidade Regional de Blumenau (FURB). Email: julianeregina.s@gmail.com

\section{Thamires Foletto Fiuza}

Pesquisadora em Turismo. Mestre em Turismo e Hotelaria pela Universidade do Vale do Itajaí (UNIVALI). Bacharel em Turismo pela Universidade Federal do Rio Grande (FURG).Email: thamires.fiuza@edu.univali.br 